\title{
Biomechanical Analysis of Explosive Strength of Legs of Athletes
}

\author{
Baljinder Singh, Ashok Kumar and M.D. Ranga
}

\begin{abstract}
Aim: The purpose of the study was to analyze the explosive strength variables of legs of athletes of different sports. Method: The study was conducted on 45 male players (fifteen handball players; age: $15.80 \pm 0.68$ years, fifteen football players; age: $16.13 \pm 0.83$ years $\&$ fifteen basketball players; age: $16.40 \pm 0.83$ years) of Punjab State coaches in Patiala (India).Results: The results of the study shows that the basketball players performed better in explosive strength parameters like the squat jump flight time, squat jump height, counter movement jump height, counter movement flight time, peak power $(45-60 \mathrm{sec})$ and mean power $(0-60 \mathrm{sec})$, then the football and handball players. The least performance was recorded by the handball players. The results also indicate that there was a highly significant correlation exists among the various explosive strength variables. Conclusion: The explosive strength variables measurement could be used by coaches to plan or adjust the training program of athletes.
\end{abstract}

Baljinder Singh

Biomechanics Scientist, Punjab State Institute of Sports, Mohali, Punjab, India

E-mail: bali007@ rediffmail.com

Ashok Kumar

Associate Professor

Department of Sports Science, Punjabi University Patiala,

Punjab, India

M. D. Ranga

Senior Scientific Officer, Department of Biomechanics,

SAI NS NIS Patiala, Punjab, India

\author{
Key Words: Explosive Strength, \\ Vertical Jump Performance, Peak \\ Power, Muscular Power
}

DOI: $10.18376 / j e s p / 2017 / v 13 / i 1 / 111271$

\section{Introduction}

The explosive strength is an action that is accomplished with maximum effort in a minimum amount of time. The basis for explosive strength is in speed-strength, a physical quality displayed in many sports skills such as jumping for maximum height (Rousanoglou et al., 2008), hitting for maximum power or distance (Silvia et al., 2009), running at top speed (Sannicandro et al., 2014), throwing for maximum distance or power (Samah, 2016) and kicking for distance or power (Nurper O., 2015). Successful sporting performance at elite levels of competition often depends heavily on the explosive leg power of the athletes (Cabri et al.,1988; Bangsbo, 1994, Stølen et al., 2005, Silvia et al., 2009). Coaches and trainers are greatly interested in developing training techniques designed to improve and measure the explosive strength and power performance of the legs of the athletes (Blattner, Stuart 1978, Haff et al., 2015). Vertical Jump (VJ) has widely been used by sports performance professionals as direct assessment method to measure the explosive strength in the lower limbs (Arteaga et al., 2000, Hara et al., 2006, Sargent 1921, Bosco et a;1., 1983) and to know the effectiveness of training programs (Hara et al., 2006, Peterson et al., 2006, Nicole et al. 2015). The VJ performance is a complex movement including several factors i.e. the maximal force developed by the muscles, the rate of force developed and the neuromuscular coordination of the upper and lower body segments ((Brian R.1998, Hopkins 2000, Sargent 1921). Some common explosive strength measures calculated from the VJ tests are the peak power (PP) or mean power (MP). Power is the product of muscular force and velocity or as an instantaneous value during a given movement. The latter, often referred to as peak power (PP), is typically associated with 


\section{Journal of Exercise Science \& Physiotherapy, Vol. 13, No. 1, 2017

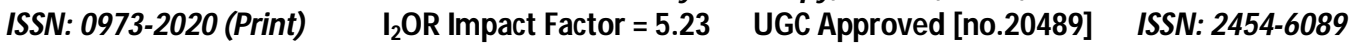 \\ (Online)}

explosive strength movements such as sprinting, jumping and may be an important variable associated with success in a given sport discipline. The measurement of PP or explosive strength by strength and conditioning-coaches is an important consideration in the training process. Changes in PP throughout the annual plan may be indicative of training status or adaptation to the workload and could be used to plan or adjust the training program based on the athlete's performance. The knowledge of explosive strength components of lower extremities of athletes of selected game disciplines can be of great interest for coaches and sport scientists to optimize talent selection in many sports disciplines. Therefore, the purpose of the study was to measure, compare and find the relationship between the explosive strength variables of legs of athletes of different sports.

\section{Materials and Methods}

Forty five $(n=45)$ male players (fifteen handball players; age: $15.80 \pm 0.68$ years, fifteen football players; age: $16.13 \pm 0.83$ years \& fifteen basketball players; age: $16.40 \pm 0.83$ years) briefed for the purpose of the study and the experimental protocol (Bosco et al., 1983, Mcguigan et al., 2006) comprising of players training under the guidance of Punjab State coaches in Patiala (India). All the risks involved were also explained to each player and voluntary consent was taken from them. Each volunteer was first subjected to physical examination that include measurements of corporal data like date of birth, age, training age, height, body mass and sports discipline. The vertical jump test or explosive strength measurement system consisted of a portable hand-held computer unit connected to a contact mat (Swift Performance, New South Wales, Australia) (Figure 1). It has been previously reported that the system is reliable compared with a force platform (Cronin et al., 2001). Three jumps: Squat jump (SJ), Counter movement jump (CMJ) and Continuous vertical jump Test for 60 seconds (CVJT) were performed by the subjects according to the experimental protocol (Bosco et al., 1983, Mcguigan et al., 2006) (Figure 2). The participants performed an adaptation process prior to the vertical jump test so that error could be minimized. The participants were told to perform a 15-minute routine warm-up before performing the tests through stretching, running, coordination exercises and consecutive jumps (two sets of five vertical jumps). Three squat jumps (SJ) and three counter movement jumps (CMJ) were performed in random order on a jump mat connected to an electronic timer without the aid of an arm swing; this was standardized by having participants hold their hands on their hips. Two minutes rest period between attempts was established. The SJ involved the subject flexing the knee to approximately 90 degree maintaining the position for 3 seconds, and then jumping on the command "go." The CMJ was performed under the same conditions but involved flexion of the knee followed immediately by extension of the legs. Test was executed following the original protocol for both jumps (Sayers SP, et al., 1999). On the next day, again the participants performed a 15-minute routine warm-up before the tests through stretching, running, coordination exercises and consecutive jumps (two sets of five vertical jumps). The participants were told to perform the continuous vertical jump Test (CVJT) during a work performed at maximal effort, with no pauses between jumps for 60 seconds. The subjects were told to keep chest in vertical position, with no excessive advance to avoid influence in the results; as well as to keep knees in extension during the flight, remaining with hands around waist. The participants were given stimulus to jump the highest as possible during the tests. 


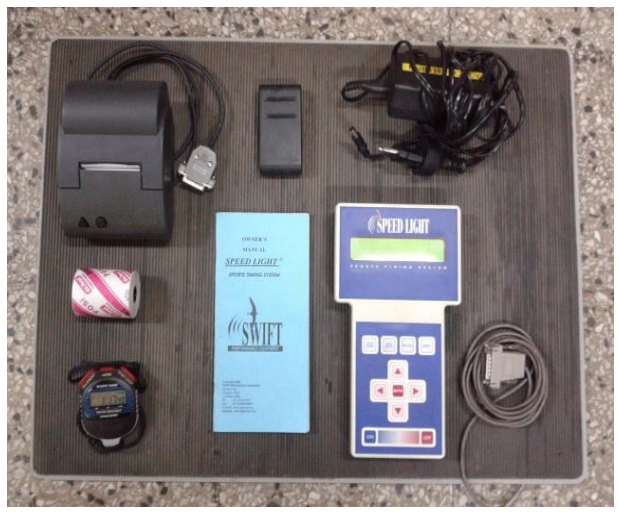

Figure 1. Portable Contact Timing Mat System (Thermal Printer, Thermal Paper, Stop Watch, Contact Mat, Data Cable, Data Recording Unit)

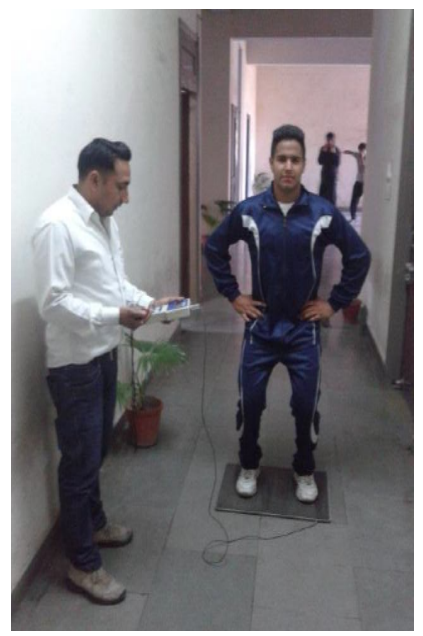

Figure 2. Squat Jump Test measurement with Contact Timing Mat System

\section{Explosive Strength Variables}

The biomechanical variables of three vertical jump tests i.e. squat jump height and squat jump flight time, counter movement jump height and counter movement jump flight time, eccentric utilization ratio, elasticity index, peak power $(0-15 \mathrm{sec})$, peak power $(45-60 \mathrm{sec})$, mean power $(0-60 \mathrm{sec})$ and fatigue index were calculated. The Eccentric Utilization Ratio (EUR) was calculated from vertical jump height (CMJ/SJ) or peak power (CMJ/SJ) by using Sayers et al (1999) peak power formula (Mcguigan et al., 2006). Muscle Elasticity index was calculated from the jump height reached in CMJ and SJ Jumps (CMJ - SJ *100 / SJ) (Francisco et al., 2010, 2011, Pradas et al., 2013, Lara et al, 2006). The explosive strength and endurance variables were power peak (PP), mean power (MP) and fatigue index (FI). Concerning the CVJT (continuous vertical jump test), the Peak Power was estimated by the mechanical power produced in the first 15 seconds of a 60 -second work. The 


\section{Journal of Exercise Science \& Physiotherapy, Vol. 13, No. 1, 2017 \\ ISSN: 0973-2020 (Print) I2OR Impact Factor $=5.23$ UGC Approved [no.20489] ISSN: 2454-6089 \\ (Online)}

Mean Power was estimated by the amount of work during a 60-second continuous effort. For PP and MP, the results were expressed in watts $/ \mathrm{kg}$ (W/ $\mathrm{kg}$ ), according to the equation described by Bosco et al. (1983) (Bosco et al., 1983, Kirkendall et al., 1986, Kums et al., 2005, Jefferson et al., 2006, 2007). The fatigue index (FI) was calculated as the difference between the power peak (work produced in the first 15 seconds) and the mean power generated in the last 15 seconds of a continuous vertical jump work of 60 seconds relative to first 15 seconds peak power. The result was expressed in percentage (\%) (Jefferson et al., 2006, 2007, Kums et al., 2005). The following formulas were used to calculate various biomechanical variables related to jump tests:

1. Peak Power or Mean Power $(\mathrm{W})=(\mathrm{Ft} \times \mathrm{Ts} \times \mathrm{g} 2) / 4 \mathrm{n}(\mathrm{Ts}-\mathrm{Ft})$ (Bosco et al., 1983, Kirkendall et al., 1986, Kums et al., 2005, Jefferson et al., 2006, 2007)

The average power generated (W) is calculated from the test duration (Ts) from 0 to 60 second, the number of jumps (n), total flight time (Ft) and where $\mathrm{g}$ is the acceleration due to gravity. The unit of mechanical power per mass unit is Watts per $\mathrm{kg}(\mathrm{W} / \mathrm{kg})$.

2. Eccentric Utilization Ratio $(\mathrm{EUR})=$ vertical jump height $(\mathrm{CMJ} / \mathrm{SJ})$ or peak power $(\mathrm{CMJ} / \mathrm{SJ})$ (Mcguigan et al., 2006)

3. Muscle Elasticity Index (EI): [(CMJ-SJ)/SJ]*100) (Francisco et al., 2010, 2011, Pradas et al., 2013, Lara et al, 2006)

4. Fatigue Index (FI): Peak Power (0-15sec) - Mean Power (45-60sec)/Peak Power $(0-15 \mathrm{sec}) \times 100$ (Jefferson et al., 2006, 2007, Kums et al., 2005)

Mean and standard deviation for all the attributes age, height, body mass and biomechanical transients related to explosive strength of legs were calculated. To observe the difference and relationship in the means of the various anthropometric and biomechanical variables among different sports, One-way Analysis of Variance (ANOVA), Scheffe Post Hoc Test and Karl Pearson's coefficient of correlation tests were applied with the help of SPSS software.

\section{Results}

Table 1 shows that the basketball players performed better in explosive strength parameters like the squat jump height, squat jump flight time, counter movement jump height, counter movement flight time, peak power $(45-60 \mathrm{sec})$ and mean power $(0-60 \mathrm{sec})$, then the football and handball players. The football players recorded the highest values in the peak power $(0-15 \mathrm{sec})$, which showed that this game require more explosive power at the start of the movement. The least performance in the tests was recorded by the handball players.

Table 2 shows the significant difference in the selected biomechanical variables of explosive strength after applying the Scheffe Post Hoc test among the handball, football and basketball players.

Tables 3 shows that there is a highly significant correlation exists between the various anthropometric and biomechanical variables of combined group $(\mathrm{N}=45)$.

Table 1. Descriptive Statistics of Anthropometric and Biomechanical Variables of Players of Different Sports

\begin{tabular}{lcccc}
\hline Variables & $\begin{array}{c}\text { Handball } \\
\mathbf{N = 1 5} \\
(\text { Mean } \pm \text { SD })\end{array}$ & $\begin{array}{c}\text { Football } \\
\mathbf{N = 1 5} \\
(\text { Mean } \pm \text { SD })\end{array}$ & $\begin{array}{c}\text { Basketball } \\
\text { N=15 } \\
(\text { Mean } \pm \text { SD })\end{array}$ & $\begin{array}{c}\text { Total Sample } \\
\text { N=45 } \\
(\text { Mean } \pm \text { SD })\end{array}$ \\
\hline Age (years) & $15.80 \pm 0.68$ & $16.13 \pm 0.83$ & $16.40 \pm 0.83$ & $16.11 \pm 0.80$ \\
Height $(\mathbf{c m})$ & $175.87 \pm 5.18$ & $174.40 \pm 4.36$ & $181.87 \pm 6.29$ & $177.38 \pm 6.15$ \\
Weight $(\mathbf{k g})$ & $58.40 \pm 6.97$ & $56.13 \pm 4.42$ & $64.60 \pm 8.61$ & $59.71 \pm 7.64$
\end{tabular}


Journal of Exercise Science \& Physiotherapy, Vol. 13, No. 1, 2017

ISSN: 0973-2020 (Print) $\quad I_{2}$ OR Impact Factor $=5.23 \quad$ UGC Approved [no.20489]

(Online)

\begin{tabular}{lcccc} 
SJ-JH(cm) & $25.47 \pm 3.87$ & $26.93 \pm 5.61$ & $32.53 \pm 4.36$ & $28.31 \pm 5.51$ \\
SJ-FT(sec) & $0.46 \pm 0.03$ & $0.47 \pm 0.04$ & $0.52 \pm 0.03$ & $0.48 \pm 0.04$ \\
CMJ-JH(cm) & $28.80 \pm 3.12$ & $30.00 \pm 5.79$ & $35.00 \pm 4.28$ & $31.27 \pm 5.19$ \\
CMJ-FT(sec) & $0.48 \pm 0.02$ & $0.49 \pm 0.04$ & $0.53 \pm 0.03$ & $0.50 \pm 0.04$ \\
EUR & $1.10 \pm 0.06$ & $1.09 \pm 0.05$ & $1.06 \pm 0.04$ & $1.08 \pm 0.05$ \\
EI & $13.97 \pm 9.36$ & $11.88 \pm 6.75$ & $7.81 \pm 5.02$ & $11.22 \pm 7.55$ \\
PP15(w/kg) & $15.81 \pm 3.13$ & $20.03 \pm 4.37$ & $19.90 \pm 3.74$ & $18.58 \pm 4.19$ \\
PP45(w/kg) & $11.77 \pm 2.70$ & $13.52 \pm 2.63$ & $14.25 \pm 3.52$ & $13.18 \pm 3.10$ \\
MP60(w/kg) & $13.61 \pm 2.41$ & $15.96 \pm 2.23$ & $16.81 \pm 3.17$ & $15.46 \pm 2.92$ \\
FI & $23.57 \pm 18.66$ & $31.16 \pm 13.87$ & $27.99 \pm 13.76$ & $27.57 \pm 15.56$ \\
\hline \multicolumn{2}{c}{ SJ- Squat Jump; SJFT- Squat Jump Flight Time; CMJJH- Counter Movement Jump Jump-Height; } \\
CMJFT-Counter; Movement Jump Flight Tim; EUR-Eccentric Utilization Ratio; EI-Elasticity \\
Index; PP- Peak Power; MP- Mean; Power; FI - Fatigue Index
\end{tabular}

Table 2. Scheffe Post Hoc Analysis of Biomechanical Variables of Players of Different Sports

\begin{tabular}{lcccc}
\hline Dependent Variable & (I) Groups & (J) Groups & $\begin{array}{c}\text { Mean } \\
\text { Difference (I-J) }\end{array}$ & Sig. \\
\hline SJJH & Handball & Football & -1.4667 & .693 \\
& & Basketball & $-7.0667 *$ & .001 \\
& Football & Basketball & $-5.6000^{*}$ & .008 \\
SJFT & Handball & Football & $-1.2800 \mathrm{E}-02$ & .646 \\
& & Basketball & $-5.9400 \mathrm{E}-02^{*}$ & .000 \\
& Football & Basketball & $-4.6600 \mathrm{E}-02^{*}$ & .006 \\
CMJH & Handball & Football & -1.2000 & .770 \\
& & Basketball & $-6.2000^{*}$ & .002 \\
& Football & Basketball & $-5.0000^{*}$ & .016 \\
CNMJFT & Handball & Football & $-9.8667 \mathrm{E}-03$ & .766 \\
& & Basketball & $-4.9267 \mathrm{E}-02^{*}$ & .003 \\
& & Basketball & $-3.9400 \mathrm{E}-02^{*}$ & .020 \\
PP15 & Football & $-4.2145^{*}$ & .015 \\
& Handball & Football & -019 \\
& & Basketball & $-4.0879 *$ & .019 \\
MP60 & Football & Basketball & .1267 & .996 \\
& Handball & Football & -2.3582 & .060 \\
& & Basketball & $-3.2068^{*}$ & .007 \\
& \multirow{2}{*}{ Football } & Basketball & -.8486 & .680 \\
\hline
\end{tabular}

*The mean difference is significant at the .05 level.

SJ- Squat Jump; SJFT- Squat Jump Flight Time; CMJJH- Counter Movement Jump Jump-Height; CMJFT- Counter; Movement Jump Flight Time; PP- Peak Power; MP- Mean

Table 3. Correlation Matrix of various Anthropometric and Biomechanical Variables of Players of Different Sports $(\mathrm{N}=45)$

\begin{tabular}{|c|c|c|c|c|c|c|c|c|c|}
\hline ariables & SJJH & SJFT CMJ & JMJ & EUR & EI & PP15 & PP45 & MP60 & FI \\
\hline ars) & .187 & $\begin{array}{ll}.193 & .183\end{array}$ & .174 & -.165 & -.095 & -.018 & .004 & .027 & .027 \\
\hline Hei & $.449 * *$ & $.464 * * .459 * *$ & $.451 * *$ & -.221 & -.172 & .030 & -.134 & -.031 & .147 \\
\hline Weight & $.334 *$ &. $\mathbf{3 3 3}^{*} \quad .289$ & $.297 *$ & $-.399 * *$ & -.208 & .080 & -.096 & -.014 & .152 \\
\hline JJH & - & $.992 * * .952 * *$ & $.949 * *$ & $-.515 * *$ & $.542 * *$ & $.553 *$ & $539 * *$ & $.589 * *$ & -.007 \\
\hline SJFT & & $.950 * *$ & $.952 * *$ & $-.502 * *$ & $.533 *$ & .559 & $505 *$ & $.576 * *$ & .037 \\
\hline
\end{tabular}


(Online)

\begin{tabular}{|c|c|c|c|c|c|c|c|}
\hline СМJH & - & $.991 * *$ & -.238 & -.264 & $.539 * .472 * *$ & $* .535 * *$ & .047 \\
\hline CNMJFT & & - & -.257 & -.283 & $.527 * .457 * *$ & $* .528 * *$ & .061 \\
\hline EUR & & & - & $.965 * *$ & $-.244-.353 *$ & $*-.350 *$ & .135 \\
\hline EI & & & & - & $-.289-.380 *$ & $*-.398 * *$ & .109 \\
\hline PP15 & & & & & $-\quad .517 * *$ & $* .804 * *$ & $.436 * *$ \\
\hline PP45 & & & & & - & $.873 * *$ & $.516 * *$ \\
\hline MP60 & & & & & & - & -.102 \\
\hline
\end{tabular}

\section{Discussion}

The explanation of the results of this study can be sought from the different mechanical behaviour of the leg extensor muscle variables involved during the vertical jump tests performed by players of different sports disciplines. The power output recorded during the jumping test does not measure only the power of the chemo-mechanical conversion but also use the mechanical energy stored in the elastic elements of the body (Cavagna et al. 1971, 1972; Asmussen and Bonde-Petersen 1974a, 1974b; Thys et al. 1972, 1975; Komi and Bosco 1979; Bosco et al. 1981b, 1981c). The findings of the present study revealed that there is a significant difference exists in the various biomechanical variables of vertical jump tests conducted on football, basketball and handball players. Differences obtained in the variables of vertical jump tests could be due to genetic factors and acute or prolonged effects of training regimen (Ostojic et al., 2010). Francisco et al., (2010) observed that the average squat jump height $15.8 \pm 4.2 \mathrm{~cm}$, flight time $357 \pm 44.4 \mathrm{msec}$, counter movement jump height $16.9 \pm 4.8 \mathrm{~cm}$, flight time $369.0 \pm 49.9 \mathrm{msec}$ and elasticity index $7.1 \pm 3.2$ for male table tennis players (age $11.32 \pm 1.82$ years). Whereas in the present study the highest values of SJ and CMJ were registered by the basketball players i.e. squat jump height was $32.53 \pm 4.36 \mathrm{~cm}$, flight time $520 \pm 30 \mathrm{msec}$ and mean counter movement jump height $35.00 \pm 4.28 \mathrm{~cm}$, flight time $530 \pm 30 \mathrm{msec}$ was observed. The Eccentric Utilization Ration (EUR) has been suggested as a useful indicator of power performance in athletes. A high EUR means that an athlete has a high capacity to store potential energy in the elastic components of the tendons and muscle and then release this energy when the tendon and muscle is shortened. McGuigan et al., (2006) observed the average value of Eccentric Utilization Ration (EUR) 1.03 \pm 0.20 for male soccer players, $1.00 \pm 0.17$ for softball male players, $1.03 \pm 0.20$ for football male players \& $1.01 \pm 0.20$ for rugby male players. In the present study the highest values of EUR and elasticity index were registered by the handball players i.e. EUR was $1.10 \pm 0.06$ and EI was 13.97 \pm 9.36 . Additional data by McGuigan et al (2006) demonstrated a significant difference between the EUR measured during the off-season and the EUR measured during the pre-season period for field hockey players. Coaches could quickly and easily conduct the necessary jump tests to determine an athlete's EUR and predict the athlete's readiness for competition. Francisco et al., (2010) observed that the elasticity index was higher in female players than in male players. The highest values of average Peak Power $(0-15 \mathrm{sec})$ in CVJT was registered by the football players i.e. $20.03 \pm 4.37 \mathrm{~W} / \mathrm{kg}$, highest average Mean Power $(0-60 \mathrm{sec})$ was registered by the basketball players i.e. $16.81 \pm 3.17 \mathrm{~W} / \mathrm{kg}$ and highest fatigue index value was registered by the handball players i.e. 23.57 \pm 18.66 . Bosco et al. (1983) found that average Mean Power (0-60sec) for school going Boys (age 17.3 \pm 0.8 years) was $22.2 \pm 1.8 \mathrm{~W} / \mathrm{kg}$. Jefferson et al., (2007) found the average Peak Power $(0-15 \mathrm{sec}) 27.76 \pm 3.78 \mathrm{w} / \mathrm{kg}$, Mean Power $(0-60 \mathrm{sec}) 19.56 \pm 2.59 \mathrm{w} / \mathrm{kg} \&$ fatigue index (\%) (FI) 48.60 \pm 7.01 for male volleyball players (age 19.01 \pm 1.36 years). In another study by Jefferson et al., (2006) of the Intermittent vertical jump tests (IVJT) observed the average Peak Power was $(0-15 \mathrm{sec}) 24.68 \pm 2.70 \mathrm{w} / \mathrm{kg}$, Mean Power $(0-60 \mathrm{sec}) 18.79 \pm 2.23 \mathrm{w} / \mathrm{kg} \&$ fatigue index $(\%)$ $57.50 \pm 9.51$ for the male handball and basketball players (age of handball players $25.74 \pm 4.71$ years 


\section{Journal of Exercise Science \& Physiotherapy, Vol. 13, No. 1, 2017 \\ ISSN: 0973-2020 (Print) $\quad$ I $_{2}$ OR Impact Factor $=5.23 \quad$ UGC Approved [no.20489] ISSN: 2454-6089 \\ (Online)}

\& basketball players $18.60 \pm 0.77$ years). Jefferson et al., $(2006,2007)$ found the similar results of mean power, peak power in two studies conducted on volleyball, handball and basketball players. These results are in accordance with a study conducted by Viitasalo et al., (1987) which showed that the mechanical power, as well as power related to body weight, increased with calendar and skeletal ages. Similar studies were conducted by the researchers to find out the relationship among the different mechanical and explosive strength variables of legs (Bosco et al., 1983, Hoffman et al., 2000, 2002, Purvi et al., 2012, Veeramani S., 2015, Ana et al., 2015, Gorostiaga, et al., 2002).

\section{Conclusion}

In conclusion, based on the above considerations, the reported jumping test might offer the possibility of evaluating the explosive strength or mechanical power of the leg extensor muscles during explosive stretch-shortening type exercises, which involve both metabolic and mechanical behavior of skeletal muscles. The knowledge of explosive strength components of lower extremities of athletes of different game disciplines will help coaches and sport scientists to optimize talent selection for different sport disciplines. Very few studies have done on the measurement and comparison of explosive strength of legs of players of same age of different sports disciplines of Indian athletic population so far. Therefore the results of this study will serve as guidelines for coaches, trainers, players and other sports scientists working with athletes for monitoring the effect of sports training, adaptation to workload and recovery.

\section{Acknowledgements}

I would like to thank coaches and players who participated and help in the data collection for this study.

\section{References}

Ana Pereira, Aldo M. Costa, Patricia Santos, Teresa Figueiredo, Paulo Vicente João. 2015. Training strategy of explosive strength in young female volleyball players. Medicina, Volume 51, Issue 2, 2015, Pages 126-131.

Arteaga, R, Dorado, C, Chavarren, J, and Calbet, JAL. Reliability of jumping performance in active men and women under different stretch loading conditions. J Sports Med Phys Fit 40: 2634, 2000.

Asmussen E., Bonde-Petersen .1974a. Storage of elastic energy in skeletal muscles in man. Acta Physiol Scand. 91: 385-392.

Asmussen E., Bonde-Petersen F.1974b. Apparent efficiency and storage of elastic energy in human muscles during exercise. Acta Physiol Scand. 92:537-545.

Bangsbo, J. (1994).Physical conditioning training in soccer: a scientific approach. Copenhagen, Denmark: University of Copenhagen7, p. 35-44, 2005.

Blattner \& Stuart.,1978. Relative effects of isokinetic and plyometric training on the vertical jump ability of college males. Publisher: Kansas State University.1-84.

Bosco C., Ito A., Komi P.V., Luhtanen P., Rahkila P., Rusko H., Viitasalo J. 1981c\&1982. Neuromuscular function and mechanical efficiency of human leg extensor muscles during jumping exercises. Acta Physiol.Scand. 114:543-550.

Bosco C., Komi P.V., Sinkkonen K. 1981b. Mechanical power, net efficiency and muscular structure in male and female middle-distance runners. Scand J Sports Sci. 2 (2):47-51.

Bosco, C., Luhtanen, P., Komi, P.V., 1983. A simple method for measurement of mechanical power in jumping. European Journal of Applied Physiology. 50(2):273-282.

Brian R. Umberger. 1998. Mechanics of the vertical jump and two-joint muscles: implications for training. Strength and conditioning. 70-74.

Cabri, J., De Proft, E., Dufour, W. \&Clarys, J. (1988). The relation between muscular strength and kick performance. In: Science and Football. Eds: Reilly, T., Lees, A., Davids, K. And Murphy, W. London: E \& FN Spon. 186-193.

Cavagna G.A., Komarek L., Citterio G., Margaria R. 1971. Power output of the previously stretched muscle. IVied Sport. 6:159-167. 


\section{Journal of Exercise Science \& Physiotherapy, Vol. 13, No. 1, 2017 \\ ISSN: 0973-2020 (Print) I2OR Impact Factor $=5.23$ UGC Approved [no.20489] ISSN: 2454-6089 \\ (Online)}

Cavagna G.A., Zamboni A., Faraggiana R., Margaria R. 1972. Jumping on the moon: Power output at different gravity values. Aerosp Med. 43: 408-414.

Cronin, J.B., McNair, P.J., Marshall, R.J., 2001. Relationship between strength qualities and motor skills associated with court performance. J Hum Mov Stud. (40), 207-224.

Francisco P., Luís C. \& Pablo F., 2010. Muscular Power of Leg Extensor Muscles in Young Toplevel Table Tennis Players. International Journal of Table Tennis Sciences. 6,178-180.

Francisco P., Marta R., Pilar M., Carlos C., Vanessa B. and Luis C., 2011. An analysis of jumping force manifestation profile in table tennis. The 12th ITTF Sports Science Congress. May 57, Rotterdam, The Netherlands.19-23.

Gorostiaga, E.M., Izquierdo, M., Ruesta, M., Inbarren, J., Gonzalez-Badillo, J., \& Ibanez, J., 2002. Effects of explosive type strength training on force production, sprint performance, endurance and serum hormones in soccer players. Medicine and Science in Sports and Exercise. 34(5), 37-45.

Haff, G. Gregory, Stone, Michael H. 2015. Methods of developing power with special reference to football players. Strength \& conditioning journal, december 2015 - volume 37 - issue 6 - p 2-16.

Hara, M, Shibayama, A, Takeshita, D, and Fukashiro, S. The effect of arm swing on lower extremities in vertical jumping. J Biomech 39: 2503-2511, 2006.

Hoffman J. R., and Kang J. 2002. Evaluation of a new anaerobic power testing system. J. Strength Cond. Res. 16(1):142-148.

Hoffman J.R., S. Epstein, M. Einbinder, and Y. Weinstein. 2000. A comparison between the Wingate anaerobic power test to both vertical jump and line drill tests in basketball players. J. Strength Cond. Res. 14: 261-264.

Hopkins WG. Measures of reliability in sports medicine and science. Sports Med 30: 1-15, 2000.

I sannicandro, a piccinno, g cofano, $\mathrm{n}$ lupelli, ra rosa. Explosive strength capacity in the lower limbs and speed performance in young soccer players. Br j sports med 2014;48:656-657.

Jefferson E. H., Leonardo G. S. N., Miguel De A., César A. D., 2007. Assessment of explosive strength-endurance in volleyball players through vertical jumping test. Rev Bras Med Esporte.13 (3):160-163.

Jefferson E. H., Leonardo G.S. N. and Miguel de A., 2006. Reliability of the four series 15-second vertical jumping test. Rev Bras Med Esporte. 12(2):85-88.

Kirkendall D.T. And Street G.M., 1986. Mechanical Jumping Power in Athletes. Br. J. Sports Med. 20(4): 163-164.

Komi P.V.1979. Neuromuscular performance: factors influencing force and speed production. Scand J Sports Sci. 1 (1): 2-15.

Kums T., Ereline J., Gapeyeva H., Pääsuke M., 2005. Vertical Jumping Performance in Young Rhythmic Gymnasts. Biology of Sport. 22 (3): 237-246.

Lara A., Alegre M.L., Abián J., Jiménez L., Ureña A., Aguado X., 2006. The selection of a method for estimating power output from jump performance. Journal of Human Movement Studies. 50, 399-410.

McGuigan, M.R., Doyle, T.L.A., Newton, M., Edwards, D.J., Nimphius, S., Newton, R.U., 2006. Eccentric utilization ratio: Effect of sport and phase of training. J Strength Cond Res. 20(4): 992-995.

Nicole C. Dabbs, Jon A. Lundahl and John C. Garner. 2015. Effectiveness of different rest intervals following whole-body vibration on vertical jump performance between college athletes and recreationally trained females..Sports 2015, 3, 258-268.

Nurper Ozbar. 2015. Effects of Plyometric Training on Explosive Strength, Speed and Kicking Speed in Female Soccer Players. Anthropologist, 19(2): 333-339.

Ostojic S.M., Stojanović M., Ahmetović Z. 2010. Vertical jump as a tool in assessment of muscular power and anaerobic performance. Med Pregl.63(5-6):371-375.

Peterson, MD, Alvar, BA, and Rhea, MR. The contribution of maximal force production to explosive movement among young collegiate athletes. J Strength Cond Res 20: 867-873, 2006. 
(Online)

Pradas De La F., Castellar O. C., Ochiana N., 2013. Analysis of Explosive And Elastic- Explosive Strength of Lower Limbs in Spanish Young Top-Level Table Tennis Players. Gymnasium, Scientific Journal of Education, Sports, and Health. 1(14): 21-28.

Purvi K. C. and Sarla B. 2012. The Correlational Study of the Vertical Jump Test and Wingate Cycle Test as a Method to Assess Anaerobic Power in High School Basketball Players. International Journal of Scientific and Research Publications. 2 (6): 1-6.

Rousanoglou EN , Georgiadis GV, Boudolos KD. Muscular strength and jumping performance relationships in young women athletes. J Strength Cond Res. 2008 Jul;22(4):13758.

S.Veeramani. 2015. Relationship among height explosive power and Shoulder strength on spiking accuracy. Asian journal of applied research. Volume 01- issue 05-, pp-05-10.

Samah kamal.2016. Effect of functional strength training on performance level of shot put. Science, movement and health, vol. Xvi, issue 1, 2016 january 2016, 16 (1): 98-102.

Sargent DA. The physical test of a man. Am Phys Educ Rev 26: 188- 194, 1921.

Sayers S.P., Harackiewicz D.V., Harman E.A., Frykman P.N., and Rosenstein M.T., 1999. Crossvalidation of three jump power equations. Medicine and Science in Sports and Exercise. $31,572-577$.

Silvia sedano campo, 1 roel vaeyens, 2 renaat $m$. Philippaerts, 2 juan carlos redondo, 1 Ana maría de benito,1 And gonzalo cuadrado. Effects of lower-limb plyometric training on Body composition, explosive strength, and Kicking speed in female soccer players. Journal of Strength and Conditioning Research. 2009. 23(6) 1714-1722.

Stølen T, Chamari K, Castagna C, Wisløff U. Physiology of soccer: an update. Sports Med 2005: 35 (6): 501-536.

Thys H., Cavagna G.A., Margaria R. 1975. The role played by elasticity in an exercise involving movements of small amplitude. Pfluigers Arch. 354: 281-285.

Thys H., Faraggiana T., Margaria R. 1972. Utilization of muscle elasticity in exercise.32 (4): 491494.

Viitasalo J.T., Osterback L., Alen M., Rahkila P., Havas E. 1987. Mechanical Jumping Power in Young Athletes.Acta Physiol Scand.131(1): 139-145. 